\section{Estimation of the Uptake Rate} Constants for Polycyclic Aromatic Hydrocarbons Accumulated by Semipermeable Membrane Devices and Triolein-Embedded Cellulose Acetate Membranes

\author{
RUNHUI KE, ${ }^{\dagger}$ YIPING XU , ${ }^{\dagger}$ \\ ZIJIAN WANG, ${ }^{*}, \dagger$ AND \\ SHAHAMAT U. KHAN ${ }^{\ddagger}$ \\ State Key Laboratory of Environmental Aquatic Chemistry, \\ Research Center for Eco-Environmental Sciences, Chinese \\ Academy of Sciences, P.O. Box 2871, Beijing 100085, China, \\ and Department of Chemistry and Biochemistry, \\ MSN 3E2, George Mason University, 4400 University Drive, \\ Fairfax, Virginia 22030-4444
}

In this paper we report an extension of our previous work on the triolein-embedded cellulose acetate membrane (TECAM) as a passive sampling device (PSD) and describe the results from simultaneous exposure of TECAMs and triolein-containing semipermeable membrane devices (SPMDs) to PAHs in lake water for 16 days. The data obtained provided a comparison of the uptake rates of specific PAHs by the two PSDs. Using 16-day accumulation tests, similar PAH distribution patterns in TECAMs and in SPMDs $\left(R^{2}=0.89, p<0.0001\right)$ were observed. However, it was noted that TECAMs could take up greater amounts of PAHs than SPMDs (735 ng/g of TECAM vs $630 \mathrm{ng} / \mathrm{g}$ of SPMD). Uptake rate constants of TECAMs and SPMDs for 16 priority pollutant (PP) PAHs, corrected for dissolved organic carbon, ranged from 0.28 to $2.94 \mathrm{~L} \mathrm{~d}^{-1}$ and from 0.16 to $0.91 \mathrm{Ld}^{-1}$, respectively. The elimination rate constants of TECAMs were 1.4-6.7 times greater than those observed for SPMDs, thereby indicating that PAHs required shorter times to achieve equilibrium in TECAMs than in SPMDs. Thus, the results of the present study suggest that TECAMs have significant potential as a good monitor to assess the pollution of hydrophobic pollutants in aquatic environments.

\section{Introduction}

Membrane-based passive sampling devices (PSDs) are rapidly gaining wide acceptance as effective tools for assessing integrated or time-weighted concentrations of lipophilic organic chemicals in aquatic and air environments. Various designs of PSDs have been proposed and widely used to concentrate hydrophobic compounds from water, and to mimic bioconcentration $(1-4)$. The triolein-containing semipermeable membrane device (SPMD) made of low-density polyethylene (LDPE) and triolein, developed by Huckins et

* Corresponding author phone: +86-010-62849140; fax: +86-01062849140; e-mail: wangzj@rcees.ac.cn.

Chinese Academy of Sciences.

‡ George Mason University. al. (2), is the most popular passive sampling configuration for aquatic environments. Although SPMDs have been successfully used in a variety of field studies (5-8), the method suffers from the disadvantages of longer time (even over a year) required for equilibrating with strongly hydrophobic contaminants that may also result in the surficial biofouling of the sampler (9). Therefore, for an effective and efficient use of PSDs to monitor environmental contaminants, new methods should be developed to overcome these disadvantages.

Although the LDPE film of the SPMD is more resistant to biodegradation than the dialysis membranes of various other configuration PSDs, its strong hydrophobicity depresses the sampling rate of target compounds in the water phase. Conversely, cellulose membranes can achieve equilibrium more quickly than polymeric films, such as LDPE, because cellulose polymers possess hydrophilic groups-hydroxyls. In an earlier report we proposed a new type of composite membrane, a triolein-embedded cellulose acetate membrane (TECAM), as a practical and meaningful approach in the field of passive sampling technology (10). The proposed TECAM method is similar to the SPMD sampling method in which the analytes of interest diffuse from the surrounding media across the sampler membrane until their concentrations in the sampler are equilibrated with the concentrations outside the sampler. In the unique configuration of the TECAM, the triolein drops are embedded in the matrix of cellulose acetate polymers and closely adhere with the polymers. The membrane material of the TECAM is cellulose acetate, which is inexpensive and is readily available. The preparation of the TECAM is easily established in a laboratory, and the extraction procedure for target compounds is also simple, involving no cleanup procedure (11). Our previous study has demonstrated that TECAMs can efficiently and quickly accumulate hydrophobic organochlorine pesticides from water under both laboratory and field conditions (11). It has also been shown that TECAMs have the potential to concentrate ultratrace levels of strongly hydrophobic organic compounds (HOCs) from water which may be nondetectable at ambient water concentrations (11).

To compare the accumulation performance of TECAMs and SPMDs, the first-order uptake rate constants can be calculated according to the model proposed by Huckins et al. $(12-14)$ :

$$
C_{\mathrm{sm}}=\left(k_{\mathrm{u}} / k_{\mathrm{e}}\right) C_{\mathrm{w}}\left(1-\exp \left[-k_{\mathrm{e}} t\right]\right)
$$

where $C_{\mathrm{sm}}$ is the concentration of the analyte in the whole sampling matrix (ng/g), $C_{\mathrm{w}}$ is the analyte concentration in ambient water $(\mathrm{ng} / \mathrm{L}), k_{\mathrm{u}}$ is the linear uptake rate constant [(L/day)/g], $k_{\mathrm{e}}$ is the overall clearance rate constant $\left(t^{-1}\right)$ of an analyte in the matrix, and $t$ is time (days). The half-life $\left(t_{1 / 2}\right)$ of an analyte in the sampling matrix is $0.693 / k_{\mathrm{e}}$. When $k_{\mathrm{e}} t \ll 1$, chemical uptake is linear and integrative, and when $k_{\mathrm{e}} t \gg 1$, eq 1 reduces to an equilibrium model.

Several studies have demonstrated that sorptive organic carbon, especially dissolved organic carbon (DOC), interacts with lipophilic PAHs (15-17) and the resulting PAH-associated organic carbon material is not available to aquatic organisms for accumulation. One implicit assumption in the use of PSDs is that only the freely dissolved form of a chemical is available for partitioning into the membrane $(12,18,19)$. Although this assumption has not been tested rigorously, it is reasonable to incorporate a correction for organic carbon material partitioning when accumulation of hydrophobic chemicals by PSDs is studied $(20,21)$. Equation 1 can be 
modified to correct for the presence of DOC and estimate the dissolved fraction of a contaminant in water using

$$
C_{\mathrm{wd}}=M_{\mathrm{tot}} /\left(M_{\mathrm{w}}+M_{\mathrm{DOC}} K_{\mathrm{DOC}}\right)
$$

where $C_{\mathrm{wd}}$ is the concentration of the dissolved form of the analyte in the water, $M_{\mathrm{tot}}$ is the total mass of the analyte, $M_{\mathrm{w}}$ is the mass of the water, and $M_{\mathrm{DOC}}$ is the mass of dissolved organic carbon in the water. For our calculations, we have assumed that $K_{\mathrm{DOC}}$ is equal to $0.11 K_{\mathrm{ow}}$ according to the relationship derived by Burkhard et al. (22) and that, for the purpose of estimating analyte partitioning between the water and the DOC, the DOC content of the water is considered to be constant. Then eq 1 reduces to

$$
C_{\mathrm{sm}}=\left(k_{\mathrm{u}} / k_{\mathrm{e}}\right) C_{\mathrm{wd}}\left(1-\exp \left[-k_{\mathrm{e}} t\right]\right)
$$

These equations have been applied to SPMDs and other similarly constructed PSDs $(19,21,23)$.

In previous studies sampling rates of PSDs were usually estimated from the laboratory flow-through experiments (13, 14, 19). However, it is often difficult to maintain aqueous concentrations of chemicals sufficiently constant in a laboratory experiment. Therefore, we chose Meiliang Bay (at the northern tip of Taihu Lake, China) as our study site because constant concentrations of PAHs have been found in the surface waters and sediments $(24-26)$. The bound PAHs can be released from the sediment into the water phase due to chemical or microbial activities (24). Furthermore, the temperature and water flow of the lake water remain relatively constant. Thus, this field site provides excellent conditions for exposure of the TECAMs and SPMDs to the contaminated lake water.

The objectives of this investigation are to utilize the data obtained during the 16-day exposure to estimate the uptake rate constants for selected PAHs by TECAMs, to compare the obtained rates with the rates of uptake of these compounds by SPMDs, and to elucidate the potential and improvement of the TECAM as a passive sampler.

\section{Materials and Methods}

Preparation of TECAMs. The TECAMs were prepared in a clean room to reduce vapor-phase contamination. Details of the preparation of TECAMs were reported elsewhere (11). TECAMs were constructed in the same configuration: 40$50 \mu \mathrm{m}$ thick, $12 \mathrm{~cm}$ wide, and $18 \mathrm{~cm}$ long. All the TECAMs were kept in Milli-Q water before use.

Preparation of SPMDs. SPMDs were prepared according to the procedure described by Huckins et al. (27). The LDPE membrane has a thickness of $75-90 \mu \mathrm{m}$, and the ratio of membrane surface area to triolein volume is $\sim 450 \mathrm{~cm}^{2} / \mathrm{mL}$. Before the deployment, they were stored in sealed acetonerinsed stainless steel containers at $4{ }^{\circ} \mathrm{C}$.

Field Study. To compare performance, TECAMs and SPMDs were placed side by side at the site of Meiliang Bay ( $31^{\circ} 28^{\prime} 32^{\prime \prime}$ N latitude, $120^{\circ} 12^{\prime} 40^{\prime \prime}$ E longitude) in Taihu Lake, China. Each TECAM $(12 \mathrm{~cm} \times 18 \mathrm{~cm})$ was placed in a stainless steel mesh cage as a single unit. The SPMDs were secured in the same manner as the TECAMs. Fifteen TECAMs paired with fifteen SPMDs were mounted on a rack and submersed in surface water to a depth of $1 \mathrm{~m}$. The exposure lasted for 16 days (June-July 2004). The water temperature was about $19-22{ }^{\circ} \mathrm{C}$ during the period of deployment. At the time of sample collection the average linear velocity of water at the deployment site was approximately $0.18-0.22 \mathrm{~km} \mathrm{~h}^{-1}$.

Three TECAM and SPMD replicates were sampled at 1 , 2, 4, 8, and 16 days. After retrieval, surficial material was removed from TECAMs and SPMDs directly using ambient water from the site. They were then placed in sealed glass jars and transported to the laboratory, where they were stored at $4{ }^{\circ} \mathrm{C}$ awaiting analysis. Field blank TECAM and SPMD samples were collected by first rigging membranes in a sampler and then retrieving them without placement in lake water.

Surface water samples $(2 \mathrm{~L})$ were collected at 0 and 16 days during the exposure course. The samples were immediately filtered through $0.45 \mu \mathrm{m}$ glass microfiber filters (Millipore), preserved in brown glass containers with $0.5 \%$ methanol at $4{ }^{\circ} \mathrm{C}$, and processed with solid-phase extraction (SPE) within 7 days.

Sample Extraction and Fractionation. TECAM samples were rinsed with distilled water and dipped in $1 \mathrm{M} \mathrm{HCl}$ and $1 \mathrm{M} \mathrm{NaOH}$ to remove the sorptive particles on the outer surface. They were then rinsed with distilled water, wiped up with clean filter paper, and finally dialyzed in $20 \mathrm{~mL}$ of hexane for $24 \mathrm{~h}$. Dialysis solutions of TECAMs were evaporated under a gentle stream of nitrogen. TECAMs were stable and persistent in hexane, with negligible weight loss of triolein and cellulose acetate during dialysis. Therefore, no additional cleanup of samples was required in this procedure (11).

SPMDs were cleaned by scrubbing under a stream of distilled water, dipping in hexane and $1 \mathrm{M} \mathrm{HCl}$, and then rinsing briefly with acetone and 2-propanol prior to dialysis in $200 \mathrm{~mL}$ volumes of hexane at $18^{\circ} \mathrm{C}$ for two $24 \mathrm{~h}$ periods. The extracts of dialyzate were preconcentrated to $2 \mathrm{~mL}$ in a rotary evaporator (Büchi Vac V-800, Switzerland).

In the laboratory the water samples were spiked with surrogate standard (2,4,5,6-tetrachloro- $m$-xylene and PCB209) before extraction. Each water sample $(2 \mathrm{~L})$ was enriched by $\mathrm{SPE}$ using a $\mathrm{C}_{18}$ cartridge. The cartridge was eluted with 10 $\mathrm{mL}$ of dichloromethane. All the extracts were evaporated under a gentle stream of nitrogen and solvent-exchanged into hexane.

Each of the aforementioned hexane extracts of SPMDs and water samples was subjected to a glass column $(10 \mathrm{~mm}$ i.d.) containing $8 \mathrm{~g}$ of 1:2 alumina/silica gel for cleanup and fractionation. Prior to their use alumina and silica gel were baked at 250 and $180{ }^{\circ} \mathrm{C}$ for $12 \mathrm{~h}$, respectively, and then deactivated with $3 \%$ distilled water $(\mathrm{w} / \mathrm{w})$. The column was eluted with $15 \mathrm{~mL}$ of hexane, and the eluate was discarded. The column was then eluted with $70 \mathrm{~mL}$ of dichloromethane/ hexane (30:70), and this fraction contained PAHs. The eluates containing PAHs were concentrated to $0.2 \mathrm{~mL}$ under a gentle stream of $\mathrm{N}_{2}$. An appropriate amount of internal standard (hexamethylbenzene) was added to the final extract prior to instrumental analysis.

Instrumental Analysis. PAHs were analyzed using an Agilent 6890 series gas chromatograph, equipped with an Agilent 5973 Network mass-selective detector (MSD) and a DB-5 MS silica fused capillary column. Splitless injection of $1 \mu \mathrm{L}$ of sample was automatically conducted. Detection was performed using selected-ion monitoring, and the details of the instrumental conditions were reported elsewhere (26). Before sample analysis, the instrument was tuned daily with decafluorotriphenylphosphine (DFTPP). PAHs in the samples were identified by comparing their GC retention times with those of the certified standards, and their identities were further confirmed by matching their GC-MS spectra with those available in the National Institute of Standards and Technology (NIST) MS Library.

Quantitation was performed using the internal calibration method based on a five-point calibration curve for individual components. Hexamethylbenzene was used as an internal standard for PAHs in GC-MSD analyses. The concentration of each of the 16 priority pollutant (PP) PAHs was determined by an individual calibration database set up from the certified standards.

Total Organic Carbon Analysis. Samples of filtered water were analyzed by using a total organic carbon (TOC) analyzer 
TABLE 1. Selected Physicochemical Properties of 16 Priority Pollutant PAHs and Their Concentrations in the Surface Water of Meiliang Bay, SPMDs, and TECAMs Exposed for 16 Days, $n=3$

\begin{tabular}{|c|c|c|c|c|c|c|c|}
\hline compd & $\begin{array}{l}\text { no. of } \\
\text { rings }^{a}\end{array}$ & MW & $\log K_{0 w^{b}}$ & $\begin{array}{l}\text { water solubility } \\
\qquad\left(\mathrm{g} \mathrm{m}^{-3}\right)\end{array}$ & $\begin{array}{l}\text { water concn } \\
\left(\text { (ng } L^{-1}\right)\end{array}$ & $\begin{array}{c}\text { SPMD concn } \\
\text { (ng } \mathrm{g}^{-1} \text { of SPMD) }\end{array}$ & $\begin{array}{c}\text { TECAM concn } \\
\text { (ng } \mathrm{g}^{-1} \text { of TECAM) }\end{array}$ \\
\hline naphthalene & $2 \mathrm{~A}$ & 128 & 3.45 & 30.2 & 95.4 & 112.4 & 87.6 \\
\hline acenaphthylene & $2 \mathrm{~A} 1 \mathrm{C}$ & 152 & 4.08 & 3.93 & 10.5 & 17.5 & 6.2 \\
\hline acenaphthene & $2 \mathrm{~A} 1 \mathrm{C}$ & 154 & 4.22 & 3.93 & 10.7 & 19.5 & 7.8 \\
\hline fluorene & $2 \mathrm{~A} 1 \mathrm{C}$ & 166 & 4.38 & 1.9 & 19.8 & 28.5 & 31.9 \\
\hline phenanthrene & $3 A$ & 178 & 4.46 & 1.18 & 35 & 62.7 & 70.1 \\
\hline anthracene & $3 A$ & 178 & 4.54 & 0.076 & 5.9 & 10.3 & 14.5 \\
\hline fluoranthene & $3 \mathrm{~A} 1 \mathrm{C}$ & 202 & 5.20 & 0.26 & 19.2 & 150.7 & 187.9 \\
\hline pyrene & $4 \mathrm{~A}$ & 202 & 5.30 & 0.135 & 12.6 & 130.1 & 141.7 \\
\hline benz[a]anthracene & $4 \mathrm{~A}$ & 228 & 5.91 & 0.011 & 2.7 & 16.0 & 37.2 \\
\hline chrysene & $4 \mathrm{~A}$ & 228 & 5.61 & 0.0019 & 2.0 & 13.0 & 44.8 \\
\hline benzo[b]fluoranthene & $4 \mathrm{~A} 1 \mathrm{C}$ & 252 & 5.78 & 0.014 & 4.3 & 27.8 & 39.5 \\
\hline benzo[k]fluoranthene & $4 \mathrm{~A} 1 \mathrm{C}$ & 252 & 6.20 & 0.008 & 3.3 & 9.0 & 9.7 \\
\hline benzo[a]pyrene & $5 \mathrm{~A}$ & 252 & 6.35 & 0.0038 & 3.3 & 7.9 & 16.1 \\
\hline dibenzo $[a, h]$ anthracene & $5 \mathrm{~A}$ & 278 & 6.75 & 0.0005 & $<4.1^{d}$ & 11.9 & 16.2 \\
\hline indeno[1,2,3-cd]pyrene & $5 A 1 C$ & 267 & 6.51 & 0.0005 & $<3.0^{d}$ & 4.6 & 9.6 \\
\hline benzo[ $g, h, i]$ perylene & $5 A 1 C$ & 276 & 6.90 & 0.0003 & $<6.5^{d}$ & 8.1 & 13.7 \\
\hline$\sum \mathrm{PAHs}$ & & & & & & 630.0 & 734.5 \\
\hline
\end{tabular}

${ }^{a} \mathrm{~A}=$ aromatic, $\mathrm{C}=$ nonaromatic. ${ }^{b}$ Preferred or selected values from Mackay et al. (34). ${ }^{c}$ Values from Huckins et al. (13). ${ }^{d}$ The concentration in water was below the method detection limit (MDL) and is represented by the MDL.

(model TOC-5000, Shimadzu, Japan) with a nondispersive infrared detector.

Quality Control. Laboratory quality control procedures included analyses of method blanks (solvent), spiked blanks (standards spiked into solvent), matrix spikes/matrix spike, and the sample. All analyses were carried out in triplicate. The instruments were calibrated daily with calibration standards. The relative percent difference between the fivepoint calibration and the daily calibrations was $<20 \%$ for all target analyses. Method blanks, procedural blanks, and spiked blanks were routinely analyzed with the field samples. Surrogate standard was added to all the samples to monitor matrix effects. The recoveries for surrogate standard were within a fairly narrow range and, for the 16 PP PAHs, varied from $54.7 \pm 6.4 \%$ to $94.3 \pm 5.2 \%$. Measured PAH concentrations were corrected for the recovery of PAH matrix spikes. Some trace levels of lower molecular weight PAHs were detected from the blank samples, and their deduction was incorporated into the data analysis.

Statistical Analysis. All model calculations, simple linear regressions, and statistical tests were performed with the use of SPSS for Windows version 10.0 software (SPSS Inc.).

\section{Results and Discussion}

Uptake Curves. PAHs detected in the two PSDs are somewhat different from those found in water (Table 1). All 16 PP PAHs are identified in the TECAMs and SPMDs, while only 13 of them are detected in the surface water, indeno[1,2,3-cd]pyrene, dibenzo $[a, h]$ anthracene, and benzo $[g, h, i]$ perylene being the 3 not detected in the surface water. A possible reason for this phenomenon may be due to the large accumulation of strong hydrophobic compounds in TECAMs and SPMDs which results in their detection in the two PSDs, although their concentration levels in water are below the detection limit. Therefore, their method detection limits are used in the calculation of uptake rate constants. On the basis of the total weights of TECAMs and SPMDs, the total concentrations of PAHs in TECAMs and SPMDs averaged 734.5 and $630.0 \mathrm{ng} / \mathrm{g}$, respectively, after 16 days of exposure. The reason for the higher levels of PAHs accumulated in TECAMs than in SPMDs appeared to be due to the larger contact area between triolein and polymers of the TECAM (11). Furthermore, this observation may also be attributed to the different matrix types of composite membranes for the two PSDs. The cellulose acetate membrane of the TECAM is more hydrophilic than the low-density polyethylene membrane of the SPMD. Therefore, the TECAM would be expected to be more easily accessible than the SPMD for waterborne chemicals from the aqueous phase into PSDs.

To compare the time-dependent accumulation process of PAHs in the two samplers, the uptake curves for four representative $\mathrm{PAHs}$ ranging from two to five aromatic rings by TECAMs and SPMDs are shown in Figure 1. On the basis of the total weight (membrane plus triolein), the uptake rates of PAHs by the TECAMs are higher than those by the SPMDs (Figure 1). It should be noted that, during the exposure period of 16 days, PAHs with low $K_{\text {ow }}$, such as naphthalene and phenanthrene, began to approach a steady state in TECAMs, while the high- $K_{\text {ow }}$ PAHs still remained in the linear uptake phase as shown for benzo[b]fluoranthene and benzo $[a]-$ pyrene. In the case of the SPMD, the approach of a curve region could be observed for naphthalene and phenanthrene at the end of exposure, but for benzo $[b]$ fluoranthene and benzo $[a]$ pyrene, the uptake remained in the linear uptake phase similar to that observed for TECAMs. This is not surprising because in our earlier study for target compounds with similar hydrophobicity shorter equilibrium times were also observed for TECAMs compared to SPMDs (11).

Although the total PAH concentrations in TECAMs are slightly higher than in SPMDs, the results of linear regression analysis show that the compositions of PAH accumulated by TECAMs and SPMDs in a side-by-side field test are quite similar $\left(R^{2}=0.89, p<0.0001\right)$, thereby suggesting that TECAMs take up the PAHs in a manner similar to that of SPMDs.

Uptake Rate Constants. Under the experimental conditions described in this study, some deviations for PAHs with high $K_{\mathrm{ow}}$ values were observed from linear or integrative uptake by SPMDs and TECAMs (Figure 1). Therefore, all the $k_{\mathrm{u}}$ and $k_{\mathrm{e}}$ values were calculated from eq 1 by employing the Marquardt-Levenberg least-squares algorithm, with $t$ being an independent variable, $C_{\mathrm{sm}}$ a dependent variable, and $C_{\mathrm{w}}$ a constant. Calculated values of the uptake rate constant (Table 2) denote the volume of water sampled (i.e., cleared of chemical) per unit time (L/day) by a standard $1 \mathrm{~g}$ triolein SPMD or $1 \mathrm{~g}$ TECAM (both including membrane and triolein). As shown in Table 2, the coefficient of variation for TECAM $k_{\mathrm{u}}$ and SPMD $k_{\mathrm{u}}$ is less than $29 \%$ and $25 \%$, respectively. The lower individual variability indicates that, similar to SPMDs, TECAMs can also generate reproducible results. 

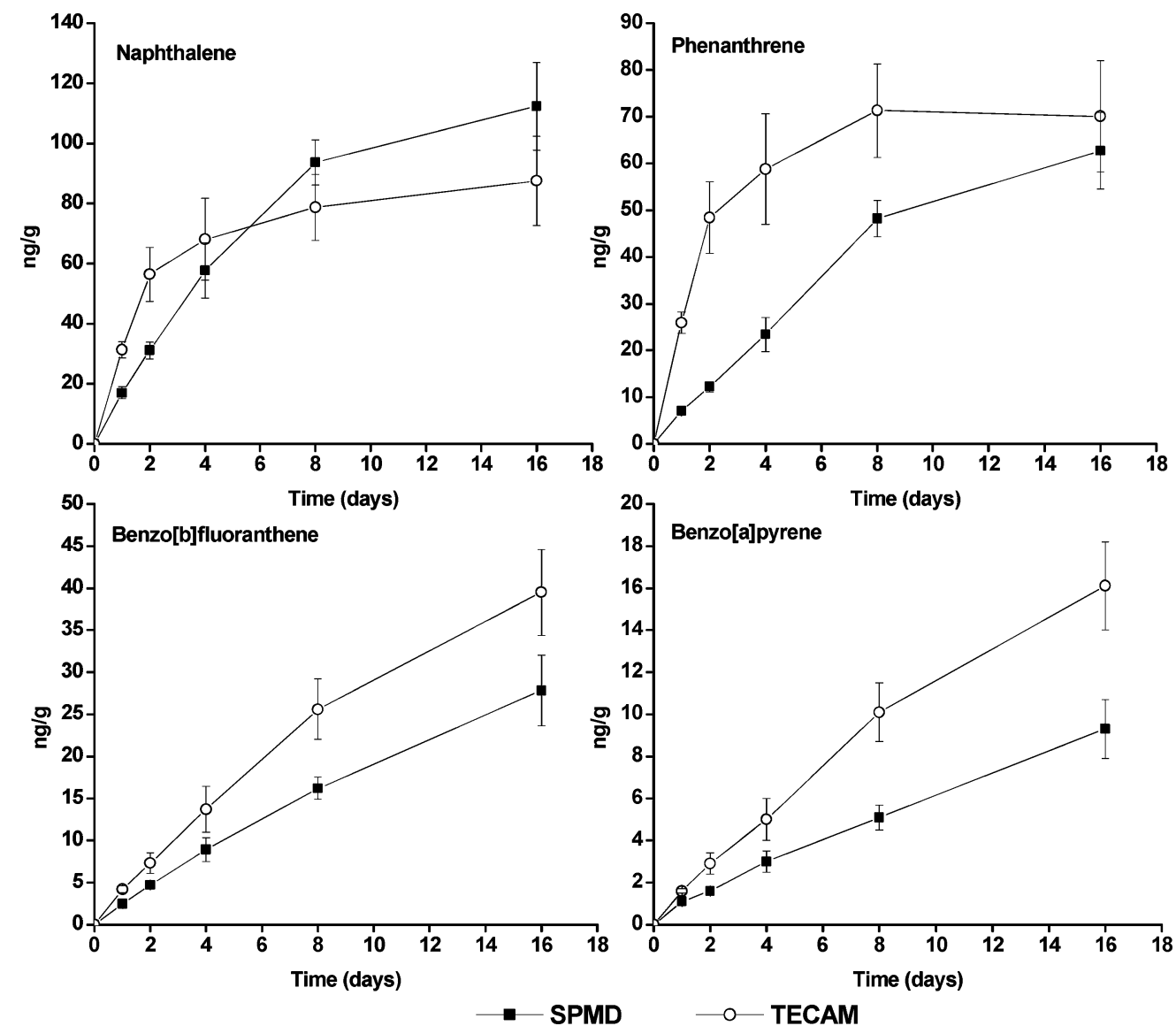

FIGURE 1. Uptake of four representative PAHs (from two to five aromatic rings) by TECAMs and SPMDs. Concentrations are based on the total weights of the TECAM and SPMD. Error bars represent standard deviations for TECAMs and SPMDs $(n=3)$.

\section{TABLE 2. Calculated PAH Uptake Rate Constants, Elimination Rate Constants, and First-Order Half-Lives for SPMDs and TECAMs} Determined from Surface Water Exposure of Meiliang Bay, Taihu Lake

\begin{tabular}{|c|c|c|c|c|c|c|c|c|c|c|}
\hline \multirow[b]{2}{*}{ compd } & \multicolumn{5}{|c|}{ SPMDs } & \multicolumn{5}{|c|}{ TECAMs } \\
\hline & $\left(\begin{array}{c}k_{\mathbf{u}} \\
\left.\mathbf{g}^{-1} \text { day }^{-1}\right)\end{array}\right.$ & $\begin{array}{l}\text { CV } \\
(\%)\end{array}$ & $\begin{array}{c}k_{\mathbf{e}} \\
\left(\text { day }^{-1}\right)\end{array}$ & $\begin{array}{c}t_{1 / 2} \\
\text { (days) }\end{array}$ & $\begin{array}{c}k_{\mathrm{u}} \text { (corrected } \\
\text { for DOC) } \\
\left(\mathrm{L} \mathrm{g}^{-1} \text { day }^{-1}\right)\end{array}$ & $\begin{array}{c}k_{\mathrm{u}} \\
\left(\mathrm{L} \mathrm{g}^{-1} \text { day }^{-1}\right)\end{array}$ & $\begin{array}{l}\text { CV } \\
(\%)\end{array}$ & $\begin{array}{c}k_{\mathrm{e}} \\
\left(\mathrm{day}^{-1}\right)\end{array}$ & $\begin{array}{c}t_{1 / 2} \\
\text { (days) }\end{array}$ & $\begin{array}{l}k_{\mathrm{u}} \text { (corrected } \\
\text { for DOC) } \\
\left(\mathrm{L} \mathrm{g}^{-1} \text { day }^{-1}\right)\end{array}$ \\
\hline naphthalene & 0.21 & 10 & 0.16 & 4.3 & 0.21 & 0.43 & 15 & 0.49 & 1.4 & 0.43 \\
\hline acenaphthylene & 0.22 & 17 & 0.11 & 6.2 & 0.22 & 0.28 & 13 & 0.47 & 1.5 & 0.28 \\
\hline acenaphthene & 0.23 & 16 & 0.10 & 6.8 & 0.23 & 0.45 & 8 & 0.60 & 1.2 & 0.46 \\
\hline fluorene & 0.16 & 21 & 0.09 & 7.7 & 0.16 & 0.97 & 11 & 0.60 & 1.2 & 0.98 \\
\hline phenanthrene & 0.23 & 8 & 0.10 & 7.0 & 0.23 & 1.02 & 17 & 0.51 & 1.4 & 1.04 \\
\hline anthracene & 0.32 & 22 & 0.07 & 9.9 & 0.33 & 0.68 & 19 & 0.28 & 2.5 & 0.70 \\
\hline fluoranthene & 0.71 & 25 & 0.05 & 13.9 & 0.77 & 1.59 & 13 & 0.14 & 4.8 & 1.73 \\
\hline pyrene & 0.82 & 14 & 0.07 & 9.9 & 0.91 & 1.97 & 27 & 0.17 & 4.0 & 2.19 \\
\hline benz[a]anthracene & 0.49 & 14 & 0.04 & 17.3 & 0.71 & 1.61 & 9 & 0.09 & 7.9 & 2.33 \\
\hline chrysene & 0.49 & 7 & 0.05 & 13.9 & 0.59 & 2.40 & 16 & 0.08 & 9.1 & 2.94 \\
\hline benzo[b]fluoranthene & 0.57 & 11 & 0.04 & 17.3 & 0.75 & 0.94 & 29 & 0.07 & 10.2 & 1.26 \\
\hline benzo[ $k]$ fluoranthene & 0.23 & 23 & 0.04 & 16.9 & 0.43 & 0.31 & 7 & 0.07 & 9.6 & 0.57 \\
\hline benzo[a]pyrene & 0.23 & 22 & 0.04 & 18.2 & 0.52 & 0.46 & 14 & 0.05 & 13.1 & 1.02 \\
\hline dibenzo $[a, h]$ anthracene & 0.25 & 24 & 0.04 & 19.8 & 0.69 & 0.41 & 11 & 0.07 & 9.6 & 1.14 \\
\hline indeno $[1,2,3-c d]$ pyrene & 0.15 & 21 & 0.04 & 16.9 & 0.62 & 0.30 & 24 & 0.06 & 11.9 & 1.24 \\
\hline benzo[ $g, h, i]$ perylene & 0.12 & 17 & 0.03 & 21.0 & 0.65 & 0.19 & 13 & 0.05 & 15.1 & 0.99 \\
\hline
\end{tabular}

The calculated uptake rate constants of PAHs by TECAMs are on the average 2.6 times higher than those of SPMDs (Table 2). For PAHs across the full range of log $K_{\mathrm{ow}}$ values (i.e., 3.45-6.90), TECAM $k_{\mathrm{u}}$ values are about 1.3-6.0 times higher than SPMD $k_{\mathrm{u}}$ values. Xu et al. (11) observed that shorter times were needed for HOCs to approach equilibrium in TECAMs than in SPMDs in the laboratory static aqueous systems. Both the laboratory and field test results show that TECAMs accumulate HOCs more quickly than observed for SPMDs.
The calculated SPMD $k_{\mathrm{u}}$ values for most of the 16 PP PAHs are 1.0-3.1 times lower than those reported by Huckins et al. (13) under the laboratory conditions by the use of flowthrough diluters at $18^{\circ} \mathrm{C}$ with the exception of naphthalene (Table 2). In the latter case the value obtained in this study is about 1.2 times higher than that observed by Huckins et al. (13). This divergence in $k_{\mathrm{u}}$ values may be caused by differences in the experimental conditions and analytical methods used in the two studies. Water temperature is regarded as one of the factors to affect the uptake rate (13, 
28). The water temperature in the present study is higher than that of Huckins et al. (13), averaging $21{ }^{\circ} \mathrm{C}$ in our experiments compared with $18^{\circ} \mathrm{C}$ in their study. It has been shown that the contaminant uptake rate would increase with increasing temperature $(13,29)$. Thus, the effect of water temperature on the sampling rates could be eliminated. The empirical data had confirmed that exposure concentration would not affect the uptake rate (13). Thus, although there are substantial differences in exposure concentrations in the two studies, this should not influence the resulting uptake rate constants. Water flow is also one of the factors to affect the uptake rates of contaminants into SPMDs (30). Although the average linear flow velocity of lake water in the present study is relatively turbulent $\left(\sim 5 \mathrm{~cm} \mathrm{~s}^{-1}\right)$ when compared with that of the referred study $\left(\sim 0.0004 \mathrm{~cm} \mathrm{~s}^{-1}\right)$ (13), significant turbulence/mixing occurred during each water input event (every $10 \mathrm{~min}$ ) in the referred study, and that might have increased shear flow across the membrane. Therefore, it would be complicated to assess the effects of hydrodynamics on the contaminant uptake rate. The most probable factor that may contribute to the divergence is the presence of sorptive organic carbon phases in the natural lake waters. It should be noted that the water used in the referred study (13) was deep-well water with no detectable dissolved and particulate organic carbon, while the organic carbon content of the water in our experiments averaged 5 $\mathrm{mg} / \mathrm{L}$. For physical reasons SPMDs have been considered to accumulate only dissolved chemicals. Several studies have demonstrated that sorptive organic carbon, including DOC, interacted with lipophilic PAHs (15-17) and the resulting PAHs were not available to aquatic organisms for accumulation. Also, a number of investigators have suggested that the presence of dissolved organic carbon in the uptake model of SPMDs or biota would therefore lower the apparent rate of accumulation of the affected compounds $(20,21)$. The $\mathrm{PAH}$ concentrations in the water were determined by the SPE method in the present study. Qiao et al. (31) have previously shown that this extraction method failed to distinguish between dissolved and DOC-associated chemicals. Therefore, the measured $\mathrm{PAH}$ concentrations in the water reflect both dissolved and DOC-associated compounds.

TECAM $k_{\mathrm{e}}$ values are $1.4-6.7$ times higher than those observed for SPMDs (Table 2), thereby resulting in much shorter $t_{1 / 2}$ values for the test compounds. SPMD $k_{\mathrm{e}}$ values decrease with an increase of the hydrophobicity of PAHs. The observed variation trend of SPMD $k_{\mathrm{e}}$ values is consistent with the result proposed by Huckins et al. (14). Although most TECAM $k_{\mathrm{e}}$ values are of relatively large magnitude compared with those of SPMDs, they demonstrate a similar trend. This indicates that the kinetics of residue exchange of the two samplers follow the same hydrophobicity model (32). Our SPMD $k_{\mathrm{e}}$ and $t_{1 / 2}$ values agree fairly well (within approximately $1-5$-fold) with the data published by Huckins et al. $(13,14)$. It should be noted that some strongly hydrophobic PAHs are not included in the comparison because of their very linear uptake reported in the studies of Huckins et al. $(13,14)$, which precludes the determination of $k_{\mathrm{e}}$ and, thus, the $t_{1 / 2}$ values. Also, on the basis of the magnitudes of the $t_{1 / 2}$ values of PAHs in TECAMs and SPMDs, PAHs would require a shorter time to achieve equilibrium in TECAMs than in SPMDs. However, it is recognized that the steady-state concentrations for half of these PAHs would not have been achieved after our 16-day deployment period in both matrixes (a time of $4 t_{1 / 2}$ is needed to exceed $94 \%$ of the steady-state concentrations).

DOC Calibration. The two data sets of TECAM and SPMD $k_{\mathrm{u}}$ values in the present study show a consistent trend of $k_{\mathrm{u}}$ increase with $\log K_{\mathrm{ow}}$, reaching a maximum near $\log K_{\mathrm{ow}}=$ 5.6 , and then a significant reduction can be observed when $\log K_{\mathrm{ow}} \geq 6$ (Table 2). This is consistent with previous studies
$(13,21)$ that found an apparent reduction in the SPMD uptake rates at $\log K_{\mathrm{ow}} \geq 6$. Uptake rate constants of HOCs by SPMDs have been shown to increase with $K_{\text {ow }}$ until solubility, diffusion layer control, DOC sorption, and permeability limitations are evoked (33). For low- $K_{\mathrm{ow}}$ compounds uptake rates are controlled by membrane resistance. Their membrane-water partition coefficients generally increase with the triolein partition coefficients (2), and the $k_{\mathrm{u}}$ values are expected to be related to their hydrophibicities. For HOCs with increasingly large log $K_{\text {ow }}$ values, membrane resistance decreases until the rate-limiting step switches to aqueous boundary layer control. Previous work has shown that uptake of chemicals with $\log K_{\mathrm{ow}}>4.5$ is controlled by the aqueous boundary layer (13). Under boundary layer control, the $k_{\mathrm{u}}$ values are expected to decrease only slightly as the HOC $K_{\mathrm{ow}}$ values increase due to the small decrease in diffusion coefficients of high- $K_{\text {ow }}$ compounds.

One of the presumable causes that may result in the discontinuity at $\log K_{\mathrm{ow}} \geq 6$ is the steric hindrance in the membrane as there is some evidence that the molecular dimensions of the higher $K_{\mathrm{ow}}$ PAHs sterically hinder movement through the pores of the membrane $(13,21)$. At the termination of our study no apparent biofouling on the outer surface of field-deployed TECAMs and SPMDs was observed. Thus, the impedance caused by biofouling should be considered very minimal.

Another factor that may contribute to the reduction at $\log K_{\mathrm{ow}} \geq 6$ is DOC sorption. Meadows et al. (20) found that the TOC content of the water was especially critical in determining the uptake kinetics of high- $K_{\mathrm{ow}}$ compounds by SPMDs or biota because of its effect on the dissolved portion of waterborne contaminants. In their work, dissolved concentrations of PCBs with $\log K_{\text {ow }}$ greater than 7 were reduced by more than $80 \%$ when corrected for TOC. The effect of organic carbon in water on the uptake rate constants of PAHs by TECAMs and SPMDs in the present study should also be assessed due to the relatively high TOC content of the lake water. The TOC in our experiment means DOC because the water samples were filtered before analysis. Concentrations of PAHs dissolved in water are estimated using eq 2, and then the DOC-corrected concentrations are used to estimate the DOC-corrected $k_{\mathrm{u}}$ values for PAHs by TECAMs and SPMDs according to eq 3 (Table 2). These data illustrate that the apparently lower uptake rate constants of the strongly hydrophobic PAHs (log $K_{\mathrm{ow}} \geq 6$ ) became less obvious when DOC partitioning was taken into account. For PAHs having low to moderate $\log K_{\text {ow }}$ (i.e., $\log K_{\text {ow }} \leq 5.3$ ), the ratios by dividing DOC-corrected SPMD/TECAM $k_{\mathrm{u}}$ values determined in the present study into the corresponding original SPMD/ TECAM $k_{\mathrm{u}}$ values (Table 2 ) are 1.0-1.1, but for PAHs with log $K_{\mathrm{ow}} \geq 5.6$, the ratios become $1.2-5.4$. These observations further illustrate that the DOC content of water has a significant effect on the accumulation of the dissolved portion of high $\log K_{\text {ow }}$ PAHs by TECAMs and SPMDs. The reason for the apparently lower uptake rates of the more hydrophobic PAHs (based on $\log K_{\text {ow }}$ ) by TECAMs and SPMDs may be due to the extremely limited water solubility coupled with increased binding to DOC in the water, both of which limit the amount of chemical contacting the membrane surface (20). Thus, the information on the DOC content of water should be considered when the uptake rate data of PSDs generated in laboratory systems are applied to field studies. This result also shows that the uptake of HOCs is controlled by the same kinetic processes for both of the PSDs.

Method Overview and Future Developments. In view of the results of the present study, it appears that the TECAM can efficiently and quickly accumulate PAHs from water in a freshwater lake environment. TECAM PAH concentrations correlate well with SPMD PAH concentrations when the TECAMs and SPMDs are subjected to the same PAH- 
contaminated lake water exposure. The greater uptake rate constants and shorter equilibrium times for PAHs in TECAMs than in SPMDs demonstrate that TECAMs can overcome some disadvantages of commonly used SPMDs. Although more laboratory and field research is required to optimize this method (especially the effects of flow velocity and temperature on the exchange kinetics) and broaden its application data, the TECAM seems to be applied as a useful passive sampler to provide reliable, relatively inexpensive, and time-integrated methods for bioavailable pollutants in aquatic environments.

\section{Acknowledgments}

We gratefully acknowledge the support of the National Basic Research Program of China (Grant 2003CB415005) and National Natural Science Foundation of China (Grant 50538090) for conducting this research.

\section{Literature Cited}

(1) Södergren, A. Solvent-filled dialysis membranes simulate uptake of pollutants by aquatic organisms. Environ. Sci. Technol. 1987, 21, 855-859.

(2) Huckins, J. N.; Tubergen, M. W.; Manuweera, G. K. Semipermeable membrane devices containing model lipid: A new approach to monitoring the bioavaiiability of lipophilic contaminants and estimating their bioconcentration potential. Chemosphere 1990, $20,533-552$.

(3) Johnson, G. D. Hexane-filled dialysis bags for monitoring organic contaminants in water. Environ. Sci. Technol. 1991, 25, 18971903.

(4) Zabik J. M.; Aston L. S.; Seiber, J. N. Rapid characterization of pesticide residues in contaminated soils by passive sampling devices. Environ. Toxicol. Chem. 1992, 11, 765-770.

(5) Prest, H. F.; Jacobson, L. A.; Huckins, J. N. Passive sampling of water and coastal air via semipermeable membrane devices. Chemosphere 1995, 30, 1351-1361.

(6) Rantalainen, A. L.; Cretney, W. J.; Ikonomou, M. G. Uptake rates of semipermeable membrane devices (SPMDs) for PCDDs, PCDFs and PCBs in water and sediment. Chemosphere 2000, 40, $147-158$.

(7) Williamson, K. S.; Petty, J. D.; Huckins, J. N.; Lebo, J. A.; Kaiser, E. M. Sequestration of priority pollutant PAHs from sediment pore water employing semipermeable membrane devices. Chemosphere 2002, 49, 717-729.

(8) Wang, Z.; Wang, Y.; Ma, M.; Lu, Y.; Huckins, J. N. Use of trioleinSPMD to assess the bioconcentration processes of hydrophobic organic contaminants in the Huaihe River, China. Environ. Toxicol. Chem. 2002, 21, 2378-2384.

(9) Gale, R. W. Three-compartment model for contaminant accumulation by semipermeable membrane devices. Environ. Sci. Technol. 1998, 32, 2292-2300.

(10) Xu, Y.; Lv, Y.; Li, J.; Ma, M.; Wang, Z. The research on the preparation and fundamental properties of a new type of cellulose acetate composite membrane. High Technol. Lett. 2004, 14, 89-94.

(11) Xu, Y.; Wang, Z.; Ke, R.; Khan, S. U. Accumulation of organochlorine pesticides from water using triolein embedded cellulose acetate membranes. Environ. Sci. Technol. 2005, 39, 1152-1157.

(12) Huckins, J. N.; Manuweera, G. K.; Petty, J. D.; Mackay, D.; Lebo, J. A. Lipid-containing semipermeable membrane devices for monitoring organic contaminants in water. Environ. Sci. Technol. 1993, 27, 2489-2496.

(13) Huckins, J. N.; Petty, J. D.; Orazio, C. E.; Lebo, J. A.; Clark, R. C.; Gibson, V. L.; Gala, W. R.; Echols, K. R. Determination of uptake kinetics (sampling rates) by lipid-containing semipermeable membrane devices (SPMDs) for polycyclic aromatic hydrocarbons (PAHs) in water. Environ. Sci. Technol. 1999, 33, 39183923.

(14) Huckins, J. N.; Prest, H. F.; Petty, J. D.; Lebo, J. A.; Hodgins, M. M.; Clark, R. C.; Alvarez, D. A.; Gala, W. R.; Steen, A.; Gale, R.; Ingersoll, C. G. Overview and comparison of lipid-containing semipermeable membrane devices and oysters (Crassostrea gigas) for assessing organic chemical exposure. Environ. Toxicol. Chem. 2004, 23, 1617-1628.

(15) McCarthy, J. F.; Jimenez, B. D. Interactions between polycyclic aromatic hydrocarbons and dissolved humic material: binding and dissociation. Environ. Sci. Technol. 1985, 19, 1072-1075.
(16) Alberts, J. J.; Griffin, C.; Gwynne, K.; Leversee, G. J. Binding of natural humic matter to polycyclic aromatic hydrocarbons in rivers of the southeastern United States. Water Sci. Technol. 1994, 30, 199-205.

(17) Haitzer, M.; Abbt-Braun, G.; Traunspurger, W.; Steinberg, C. E. W. Effects of humic substances on the bioconcentration of polycyclic aromatic hydrocarbons: correlations with spectroscopic and chemical properties of humic substances. Environ. Toxicol. Chem. 1999, 18, 2782-2788.

(18) Hofelt, C. S.; Shea, D. Accumulation of organochlorine pesticides and PCBs by semipermeable membrane devices and Mytilus edulis in New Bedford Harbor. Environ. Sci. Technol. 1997, 31, 154-159.

(19) Booij, K.; Sleiderink, H. M.; Smedes, F. Calibrating the uptake kinetics of semipermeable membrane devices using exposure standards. Environ. Toxicol. Chem. 1998, 17, 1236-1245.

(20) Meadows, J. C.; Echols, K. R.; Huckins, J. N.; Borsuk, F. A.; Carline, R. F.; Tillitt, D. E. Estimating of uptake rate constants for PCB congeners accumulated by semipermeable membrane devices and brown trout (Salmo trutta). Environ. Sci. Technol. 1998, 32, $1847-1852$.

(21) Luellen, D. R.; Shea, D. Calibration and field verification of semipermeable membrane devices for measuring polycyclic aromatic hydrocarbons in water. Environ. Sci. Technol. 2002, 36, 1791-1797.

(22) Burkhard, L. P. Estimating dissolved organic carbon partition coefficients for nonionic organic chemicals. Environ. Sci. Technol. 2000, 34, 4663-4668.

(23) Hofelt, C. S. Use of artificial substrates to monitor organic contaminants in the contaminants in the aquatic environment. Ph.D. Dissertation, Northern Carolina State University, Raleigh, NC, 1998.

(24) Qu, W.; Mike, D.; Fan, C.; Wang, S.; Su, C.; Zhang, L.; Zou, H. Distribution, sources and potential toxicological significance of polycyclic aromatic hydrocarbons (PAHs) in Taihu Lake sediments, China. Hydrobiologia 2002, 485, 163-171.

(25) Wang, H.; Wang, C.; Wu, W.; Mo, Z.; Wang, Z. Persistent organic pollutants in water and surface sediments of Taihu Lake, China and risk assessment. Chemosphere 2003, 50, 557-562.

(26) Qiao, M.; Wang, C.; Huang, S.; Wang, D.; Wang, Z. Composition, sources, and potential toxicological significance of PAHs in the surface sediments of the Meiliang Bay, Taihu Lake, China. Environ. Int. 2006, 32, 28-33.

(27) Huckins, J. N.; Petty, J. D.; Prest, H. F.; Orazio, C. E.; Clark, R. C. Guide for the Use of Semipermeable Membrane Devices (SPMDs) as Samplers of Waterborne Hydrophobic Organic Contaminants; Report for the American Petroleum Institute (API); API Publication Number 4690; API: Washington, DC, 2000.

(28) Huckins, J. N.; Petty, J. D.; Lebo, J. A.; Orazio, C. E.; Prest, H. F.; Tillitt, D. E.; Ellis, G. E.; Johnson, B. T.; Manuweera, G. K. Semipermeable membrane devices (SPMDs) for the concentration and assessment of bioavailable organic contaminants in aquatic environments. Techniques in Aquatic Toxicology; CRC Press: Boca Raton, FL, 1996; pp 625-655.

(29) Booij, K.; Hofmans, H. E.; Fischer, C. V.; Van Weerlee, E. M. Temperature-dependent uptake rates of nonpolar organic compounds by semipermeable membrane devices and lowdensity polyethylene membranes. Environ. Sci. Technol. 2003, $37,361-366$.

(30) Huckins, J. N.; Petty, J. D.; Prest, H. F.; Orazio, C. E.; Gale, R. W. Abstracts, 18th Annual Meeting, SETAC, San Francisco, CA, Nov 16-20, 1997; Society of Environment Toxicology and Chemistry: Pensicola, FL, 1997; p 206.

(31) Qiao, P.; Farrell, A. P. Influence of dissolved humic acid on hydrophobic chemical uptake in juvenile rainbow trout. Comp. Biochem. Physiol., C 2002, 133, 575-585.

(32) Mackay, D.; Paterson, S. Calculating fugacity. Environ. Sci. Technol. 1981, 15, 1006-1014.

(33) Huckins, J. N.; Petty, J. D.; Lebo, J. A.; Orazio, C. E.; Clark, R. C.; Gibson, V. L. SPMD technology: A tutorial; Midwest Science Center, U.S. Geological Survey: Columbia, MO, 1997.

(34) Mackay, D.; Shiu, W. Y.; Ma, K. C. Illustrated Handbook of Physical-Chemical Properties and Environmental Fate for Organic Compounds; Lewis Publishers: Chelsea, MI, 1992; Vol. II.

Received for review March 2, 2006. Revised manuscript received April 14, 2006. Accepted April 18, 2006.

\section{ES060493T}

